\title{
Un paso más, adelante
}

ANALECTA VeTERINARIa se renueva con cada volumen, logrando, de esta manera, mayor visibilidad entre sus lectores habituales y los que día a día se van sumando. Nuevos integrantes se avienen a colaborar en el proceso editorial por la simple razón de devolver a la Facultad de Ciencias Veterinarias de la Universidad Nacional de La Plata todo lo que la institución les brindó en sus pasos por las aulas o los laboratorios.

En los últimos volúmenes de la revista hemos recibido casi el 100\% de trabajos con autores provenientes de instituciones ajenas a nuestra Universidad. Esto nos llena de orgullo, ya que significa que la revista trasciende las fronteras locales y hasta llega a países latinoamericanos cuyos autores nos aportan sus conocimientos y experiencias.

Un nuevo logro se alcanzó, recientemente, con el reconocimiento de la versión en línea de ANALECTA VETERINARIA por parte de Latindex (Sistema Regional de Información en Línea para Revistas Científicas de América Latina, el Caribe, España y Portugal) (https://www.latindex.org/), que es un sistema de información académica, sin fines de lucro y de consulta gratuita, especializado en revistas académicas editadas en Iberoamérica. Esto le permitirá llegar a nuestra revista hasta otras instituciones latinoamericanas y, probablemente, a través de estas, a aquellos países que aún no la conocen. De la misma manera, ANALECTA VETERINARIA ha sido aceptada, luego de una evaluación por pares, para integrar la base de datos EuroPub (http://europub.co.uk/), que cubre literatura académica e indiza artículos de revistas de todo el mundo. Su principal objetivo es aumentar la visibilidad de las revistas académicas de acceso abierto, promoviendo así su mayor uso e impacto.

Consejo Editorial

ANALECTA Veterinaria

ANALECTA Vet 2019; Enero-Junio; 39(1):1

Impresa ISSN 03655 14-8 Electrónica ISSN 1514-2590

doi.org/10.24215/15142590eo31 